UDC 54.058

\title{
ON MULTIPLE DISTILLATION OR CRYSTALLIZATION REFINING AT GIVEN YIELD
}

\section{A.I. Kravchenko, O.A. Datsenko \\ National Science Center "Kharkov Institute of Physics and Technology", Kharkiv, Ukraine E-mail:krwchnko@gmail.com}

A comparison is made of the $C_{\mathrm{n}}$ concentration of the impurity with a separation coefficient $\beta<1$ in the product of $n$-fold refining by simple distillation or normal directed crystallization with the concentration of $C_{1}$ impurity in the product of 1 -fold refining with the same initial concentration and the same final yield $G$. The dependence $C_{\mathrm{n}} / C_{1}$ from the process parameters $n, G$, and $\beta$ allowing to evaluate the feasibility of using n-fold refining instead of a single one is shown. The excess of $C_{\mathrm{n}}$ over the minimum achievable level increases with a decrease in $\beta<1$ and with an increase in $n$ and $G$.

\section{INTRODUCTION}

Distillation and crystallization are the main methods for obtaining high-purity substances, in connection with which interest in the theory and practice of these processes is maintained [1-4]. Distillation and crystallization are the main methods for obtaining highpurity substances, in connection with which interest in the theory and practice of these processes is maintained [5-8]:

$$
\frac{C}{C_{0}}=\frac{1-(1-g)^{\beta}}{g},
$$

where $C$ is average impurity content in the product (in condensate or in crystal); $C_{0}$ is initial impurity content; $g$ is degree of distillation or proportion of crystallized material (a yield of process); $\beta$ is distillation separation factor (as the ratio of the concentration of an impurity in the vapor leaving the evaporation surface to its concentration in the liquid from which the vapor is formed, near the evaporation surface) or crystallization distribution coefficient. The graphs of equation (1) for various values of $\beta<1$ are shown in Fig. 1 .

For a process with multiple repetitions, an equation is known that relates the concentration $C_{\mathrm{n}}$ of impurities in the product with the process parameters $\beta, n$, and $g$ $[1,8]$ :

$$
\frac{C_{n}}{C_{0}}=\left[\frac{1-(1-g)^{\beta}}{g}\right]^{n} .
$$

In such a process, the final yield $G$ is related to the yield $g$ of each unit process by the relation $G=g^{\mathrm{n}}$ (or $\left.g=G^{1 / n}\right)$. As follows from equations (1) and (2), at $\beta<1$, the value $C_{\mathrm{n}} / C_{0}$ has a minimum at $g \approx 0$, equal to $\beta^{\mathrm{n}}$.

There is an estimate of the economic efficiency of the processes under consideration, according to which for difficult-to-remove impurities (with a separation coefficient $\beta \sim 0.1$ ) the optimal value of the yield $g$ in each unit process is $\approx 80 \ldots 90 \%$ [8].

At the same time, if the stock of the starting material for refining is limited (for example, in refining isotope engineering materials [9-12]) there is a tendency to run processes with a particularly high yield. For example, to refine archaeological isotopically modified lead, use was made of fourfold distillation with $g \approx 99 \%$ in each cycle and, accordingly, a final yield near $96 \%$ [12]. The ${ }^{106} \mathrm{Cd}$ and ${ }^{116} \mathrm{Cd}$ isotopes were refined in the same manner [13]. (In connection with the refining of isotopes, earlier work on the distillation of polonium may also be mentioned [14]).

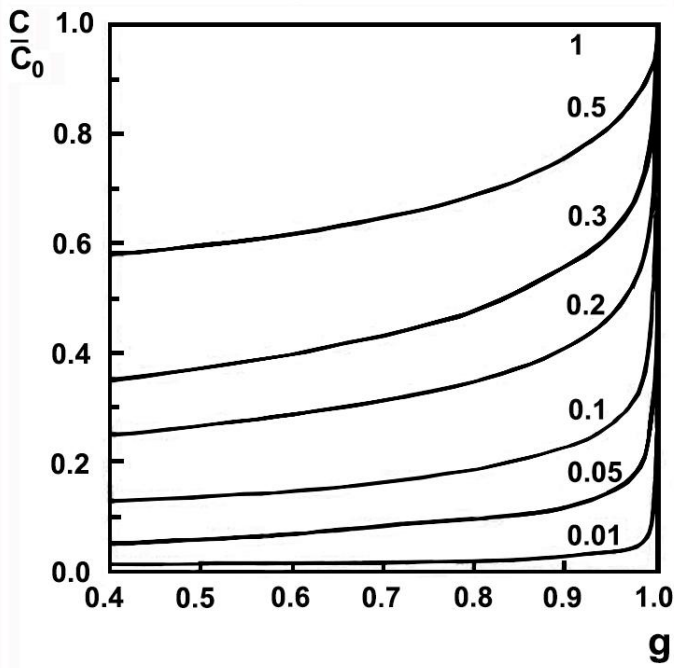

Fig. 1. The dependence of the efficiency of $C / C_{0}$ for refining a substance at $\beta<1$ from the yield $g$-according to equation (1). The numbers next to the curves indicate the corresponding values of the separation factor $\beta$

Multiple repetitions of the process with a preset yield $g$ in each cycle reduces the final yield $G=g n$ (where $n$ is the number of cycles). To increase $G$, the process can be run at increased values of $g$ and $n$. However, it is not obvious that it is reasonable to increase $g$ or $n$ at a given $G$ to reach high purification efficiency because, according to equation (1), purification efficiency in each single cycle with a yield $g$ in an $n$-fold process is lower than purification efficiency in a simple singlecycle process with a yield $G<g$ (see Fig. 1).

The purpose of this work is to study the efficiency of a multiple refining process, via simple distillation or directional solidification, as a function of process parameters-number of cycles, final yield, and separation 
factor in order to ascertain whether or not it is reasonable to use multiple refining instead of a singlecycle process. Particular attention is paid to processes with a high final yield. It was also of interest to consider the dependence of the $C_{\mathrm{n}}$ impurity concentration in the product on the process parameters in comparison with the minimum achievable level $\beta^{\mathrm{n}} C_{0}$. Some of the results of the performed research were recently presented [15], but it is possible to present them anew in a clearer and more complete form.

\section{PERFORMANCE OF CALCULATIONS}

As a criterion for whether it is reasonable to use technically complex multiple refining instead of a single-cycle process, we consider $C_{\mathrm{n}} / C_{1}$ : the ratio of impurity concentration in the multiple refining product to that in the single-cycle refining product at the same initial impurity concentration $C_{0}$ in the starting substance and the same final yield $G$. The efficiency of using the multiple-cycle process instead of singlecycle refining increases with decreasing $C_{\mathrm{n}} / C_{1}$ ratio.

Taking into account equality $g=G^{1 / n}$, equation (2) is transformed to the form:

$$
\frac{C_{n}}{C_{0}}=\frac{\left[1-\left(1-G^{1 / n}\right)^{\beta}\right]^{n}}{G} .
$$

Equation (1) is used to find the degree of product purification in a single process with the same yield $G$ :

$$
\frac{C_{1}}{C_{0}}=\frac{1-(1-G)^{\beta}}{G} .
$$

Comparing equations (3) and (4), we obtain the relative concentration of impurities in the product of a multiple process, independent of the initial concentration $C_{0}$, in comparison with a single process with the same final yield:

$$
\frac{C_{n}}{C_{1}}=\frac{\left[1-\left(1-G^{1 / n}\right)^{\beta}\right]^{n}}{1-(1-G)^{\beta}} \text {. }
$$

\section{RESULTS AND DISCUSSION}

The results of calculations using equations (1)-(5) are presented in Tables 1 and 2 and in the form of Fig. 2 (on which each pair of numbers $(n, G)$ corresponds to the number $g=G^{1 / \mathrm{n}}$ ).

$C_{\mathrm{n}} / C_{1}$ is a strong function of $\beta$. At known $\beta<1$, for each value of $G$ we can find the number of cycles, $n$, at which any small $C_{\mathrm{n}} / C_{1}$ ratio can be reached. Each new cycle is less efficient than the preceding cycle. To remove impurities with a large deviation of $\beta<1$ from unity (for example, at $\beta=0.1$ or smaller), multiple processes with a high final yield are highly efficient even in the case of a few cycles (for $n<10$ ) and relatively small $g<99 \%$ (note that, if $G$ is relatively small, the main decrease in $C_{\mathrm{n}} / C_{1}$ is ensured by the first few cycles, after which it decreases much more slowly with increasing $n$ ). At the same time, if $\beta$ is near unity, replacing the single-cycle process by a multiple-cycle one can be efficient, but only at very high values of $n$ and $g$, for example, at $n \sim 10 \ldots 100$ and $g>99.5 \%$ for $\beta=0.5$ (it is worth noting that processes with such a high value of $g$ are difficult to run).
Table 1

\begin{tabular}{|c|c|c|c|c|c|}
\multicolumn{6}{c}{$C_{\mathrm{n}} / C_{0}$ depending on $G, n$, and $\beta\left(g=G^{1 / \mathrm{n}}\right)$} \\
\hline \multirow{3}{*}{$G$} & $n$ & $g$ & $\beta=0.5$ & $\beta=0.1$ & $\beta=0.01$ \\
\hline \multirow{4}{*}{0.96} & 1 & 1 & 0.83 & 0.27 & 0.033 \\
\cline { 2 - 6 } & 2 & 0.980 & 0.77 & 0.11 & 0.002 \\
\cline { 2 - 6 } & 4 & 0.990 & 0.68 & 0.019 & - \\
\cline { 2 - 6 } & 10 & 0.996 & 0.54 & - & - \\
\hline 0.90 & 1 & 1 & 0.76 & 0.23 & 0.025 \\
\cline { 2 - 6 } & 2 & 0.95 & 0.67 & 0.07 & $6 \cdot 10^{-4}$ \\
\cline { 2 - 6 } & 4 & 0.97 & 0.55 & 0.01 & - \\
\cline { 2 - 6 } & 10 & 0.99 & 0.39 & - & - \\
\hline 0.80 & 1 & 1 & 0.69 & 0.19 & 0.020 \\
\cline { 2 - 6 } & 2 & 0.89 & 0.57 & 0.05 & $6 \cdot 10^{-4}$ \\
\cline { 2 - 6 } & 4 & 0.94 & 0.43 & 0.005 & - \\
\cline { 2 - 6 } & 10 & 0.98 & 0.25 & - & - \\
\hline
\end{tabular}

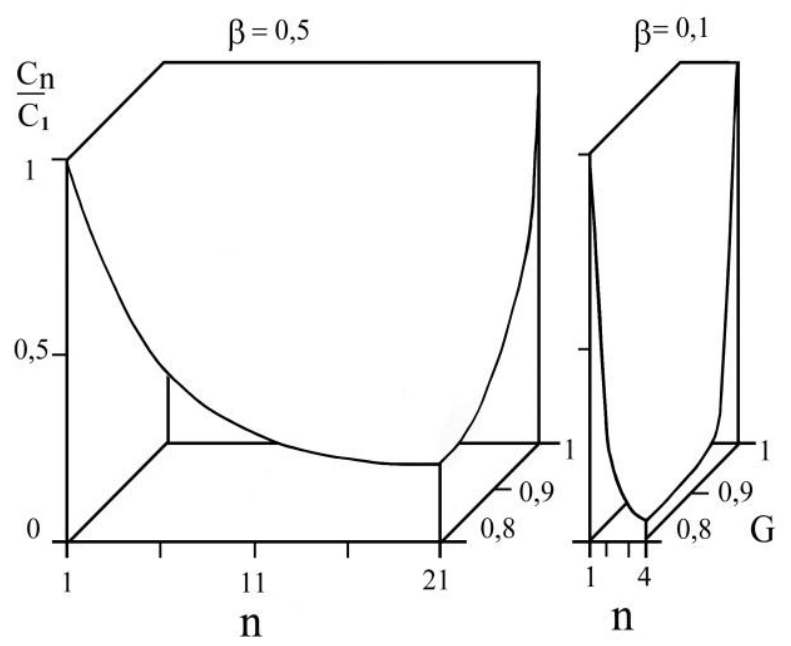

Fig. 2. Dependence $C_{n} / C_{1}$ from $n$ and $G$ at $\beta=0.5$ and $\beta=0.1$

Table 2

$C_{\mathrm{n}} / C_{1}$ depending on $G, n$, and $\beta\left(g=G^{1 / \mathrm{n}}\right)$

\begin{tabular}{|c|c|c|c|c|c|}
\hline \multirow{3}{*}{$G$} & $n$ & \multirow{2}{*}{$g$} & \multicolumn{3}{|c|}{$C_{\mathrm{n}} / C_{1}$} \\
\cline { 4 - 7 } & & & $\beta=0.5$ & $\beta=0.1$ & $\beta=0.01$ \\
\hline 0.96 & 2 & 0.980 & 0.92 & 0.41 & 0.05 \\
\cline { 2 - 6 } & 4 & 0.990 & 0.82 & 0.07 & 0.0001 \\
\cline { 2 - 6 } & 10 & 0.996 & 0.65 & 0.0007 & - \\
\cline { 2 - 6 } & 50 & 0.999 & 0.25 & - & - \\
\hline 0.90 & 2 & 0.95 & 0.88 & 0.32 & 0.04 \\
\cline { 2 - 6 } & 4 & 0.97 & 0.72 & 0.04 & $6 \cdot 10^{-5}$ \\
\cline { 2 - 6 } & 10 & 0.99 & 0.51 & - & - \\
\hline 0.80 & 2 & 0.89 & 0.82 & 0.27 & 0.03 \\
\cline { 2 - 6 } & 4 & 0.94 & 0.64 & 0.04 & $4 \cdot 10^{-5}$ \\
\cline { 2 - 6 } & 10 & 0.98 & 0.39 & 0.0001 & - \\
\hline
\end{tabular}

Results of comparison of $C_{\mathrm{n}} / C_{0}$ with the minimum achievable level $\beta^{\mathrm{n}}$, obtained using equations (1)-(4), are presented in Tables 3 and 4 . The excess of $C_{\mathrm{n}}$ over the minimum achievable level increases with decreasing $\beta<1$ and with increasing $n$ and $G$. 
Table 3 separation factor $\beta$ in an $n$-fold process. For $\beta<1$, the $n$ -

Ratio $\left(C_{\mathrm{n}} / C_{0}\right) / \beta^{\mathrm{n}}$ in depending on yield $G=g^{n}$ at different values of $\beta$ and $n=1$

\begin{tabular}{|c|c|c|c|c|}
\hline \multirow{2}{*}{$g$} & \multirow{3}{*}{$G$} & \multicolumn{3}{|c|}{$C_{1} / C_{0}$} \\
& & \multicolumn{3}{|c|}{$\beta$} \\
& & $\beta=0.5$ & $\beta=0.1$ & $\mathrm{~B}=0.01$ \\
\hline$\approx 0$ & $\approx 0$ & 1 & 1 & 1 \\
\hline 0.5 & 0.5 & 1.2 & 1.3 & 1.4 \\
\hline 0.8 & 0.8 & 1.4 & 1.9 & 2.0 \\
\hline 0.9 & 0.9 & 1.5 & 2.3 & 2.5 \\
\hline 1 & 1 & 2 & 10 & 100 \\
\hline
\end{tabular}

Table 4

Ratio $\left(C_{\mathrm{n}} / C_{0}\right) / \beta^{\mathrm{n}}$ in depending on yield $G=g^{n}$ at different values of $\beta$ and $n=2$

\begin{tabular}{|c|c|c|c|c|}
\hline \multirow{2}{*}{$g$} & \multirow{2}{*}{$G$} & \multicolumn{3}{|c|}{$\frac{C_{2} / C_{0}}{\beta^{2}}$ at different $\beta$} \\
\cline { 3 - 5 } & & $\beta=0.5$ & $\beta=0.1$ & $\beta=0.01$ \\
\hline$\approx 0$ & $\approx 0$ & 1 & 1 & 1 \\
\hline 0.5 & 0.25 & 1.4 & 1.7 & 2.0 \\
\hline 0.8 & 0.64 & 2.0 & 3.6 & 4.0 \\
\hline 0.9 & 0.81 & 2.3 & 5.3 & 6.3 \\
\hline 1 & 1 & 4 & 100 & $10^{4}$ \\
\hline
\end{tabular}

In general, equations (2), (3), and (5) make it possible to find (analytically or numerically) one of the quantities included in them $\left(\beta, C_{\mathrm{n}} / C_{1}, C_{\mathrm{n}} / C_{0}, n, G\right)$ at given the rest. Some of these tasks are covered in a preliminary publication [15]. With equals (1) and (3) the yield $G^{\prime}$ of a one-shot process can be found, in which the same cleaning is achieved as in a multiple one with given $G, \beta$, and $n$. The number $N$ of repetitions can be calculated to achieve the concentration $\beta C_{0}$ of impurities in the product $\left(\beta C_{0}\right.$ is the minimum achievable concentration of impurities in the product of a single refining):

$$
N=(\ln \beta) / \ln \frac{1-(1-g)^{\beta}}{g} .
$$

The process of $n$-fold refining of a substance containing two impurities can also be considered: with initial concentrations $C_{01}$ and $C_{02}$ and with separation factors $\beta_{1}$ and $\beta_{2}$, respectively. In the special case when $C_{01}>C_{02}$, and $\beta_{1}<\beta_{2}<1$, at a certain number $N_{2}$ of repetitions of the process, the concentrations $C_{1}$ and $C_{2}$ of impurities reach equality. The number $N_{2}$ can be calculated at given yield $G$. Using equation (5), it is easy to obtain the equation:

$$
C_{01}\left[1-\left(1-G^{1 / n}\right)^{\beta_{1}}\right]^{N_{2}}=C_{02}\left[1-\left(1-G^{1 / n}\right)^{\beta_{2}}\right]^{N_{2}},
$$

from where

$$
N_{2}=\left(\ln \frac{C_{02}}{C_{01}}\right) / \ln \frac{1-\left(1-G^{1 / n}\right)^{\beta_{1}}}{1-\left(1-G^{1 / n}\right)^{\beta_{2}}} .
$$

\section{CONCLUSIONS}

We have considered whether it is reasonable to use multiple distillation refining or directional solidification with a preset final yield $G$ instead of a single-cycle process with the same yield. An equation has been derived for the relative purification efficiency $C_{\mathrm{n}} / C_{1}$ as a function of $n$ and $G$ in the case of an impurity with a fold refining process with a yield $g$ in each cycle and a final yield $G=g n$ is more efficient than a single-cycle process with the same final yield $G$. Each new cycle is less efficient than the preceding one. At a given $G$, the relative efficiency of the $n$-fold process rises with an increase in the deviation of $\beta<1$ from unity and with increasing $n$ (with the corresponding increase in $\left.g=G^{1 / n}\right)$. The difference in efficiency between the singleand multiple-cycle refining processes decreases as the separation factor $\beta$ and the final yield $G$ approach unity. At a considerable deviation of $\beta$ from unity (at $\beta<0.1$ ) and relatively low values of $G$ (at $G<0.9$ ), the main decrease in $C_{\mathrm{n}} / C_{1}$ is ensured by the first few cycles of the process, after which it decreases markedly more slowly with increasing $n$. The excess of $C_{n}$ over the minimum achievable level increases with a decrease in $\beta<1$ and with an increase in $n$ and $G$.

\section{REFERENCES}

1. G.G. Devyatykh, Yu.E. Elliev. Glubokaya ochistka veshchestv (Ultrapurification of Substancers). M.: "Vysshaya Shkola", 1990, 192 p. (in Russian).

2. E. Ignatovich. Khimicheskaya tekhnika. Protsessy $i$ apparaty (Chemical Engineering. Processes and apparatus). M.: “Tekhnosfera”, 2007, 656 p. (in Russian).

3. Yu.I. Dytnerskii. Protsessy $i$ apparaty khemicheskoi tekhnologii: Uchebnik dlya vuzov (Processes and apparatus of chemical technology: Textbook for high schools). P. 2. Mass exchange processes and apparatus. M.: "Himiya", 1995, 368 p. (in Russian).

4. Kristallizatsiya is rasplavov: Cpravochnoe izd.: Per. s nem. Bartell I., Burig E., Haints K., Kuharzh. M.: "Metallurgiya". 1987, 320 p. (Kristallisation aus Schmelzen / K. Hein und E. Buhrig. VEB Deutscher Verlag Fur Grundstoffindustrie, Leipzig, 1983).

5. A.I. Kravchenko. Purification efficiency of distillation and crystallization processes // Inorganic materials. 2010, v. 46, N 1, p. 93-95.

6. A.I. Kravchenko. Calculation of distillation refining of a substance containing low and highly volatile impurities // Inorganic materials. 2018, v. 54, N 5, p. 501-503.

7. A.I. Zhukov, A.I. Kravchenko. Calculation of sublimation with allowance for impurity diffusion // Inorganic Materials. 2017, v. 53, N 6, p. 648-653.

8. A.Ye. Vol'pyan, G.N. Kurdyumov, V.A. Molochko. Optimization of the multiple directional solidification process // Teoreticheskiye osnovy khimicheskoy tekhnologii. 1971, v. 5, N 4, p. 602-604 (in Russian).

9. V.G. Plekhanov. Izotope engineering // Phys. Usp. 2000, v. 170, N 11, p. 1245-1252.

10. M.V. Sukhanov, T.I. Storozheva, I.I. Evdokimov, et al. Fine purification of monoisotopic ${ }^{32} \mathrm{~S}$ and ${ }^{34} \mathrm{~S} / /$ Inorganic materials. 2017, v. 53, N 2, p. 142-147.

11. T.G. Sorochkina, A.D. Bulanov, A.Y. Sozin, O.Y. Chernov. Impurity composition of monoisotopic silicon tetrafluoride // Inorganic materials. 2017, v. 53, N 12, p. 1300-1306.

12. R.S. Boiko, V.D. Virich, F.A. Danevich, et al. 
Ultrapurification of archaeological lead // Inorganic materials. 2011, v. 47, N 6, p. 672-676.

13. G.P. Kovtun, A.P. Shcherban', D.A. Solopikhin, et al. Production of radiopure natural and isotopically enriched cadmium and zinc for low background scintillators // Functional Materials. 2011, N 1, p. 121-127.
14. R.W. Endebrock, P.M. Engle. The separation of polonium from bismuth by distillation. Mound Laboratory, Miamisburg, Ohio, 1953, 43 p.

15. A.I. Kravchenko. Efficiency of multiple distillation or crystallization refining with a present yield // Inorganic materials. 2020, v. 56, N 10, p. 10551058.

\section{О МНОГОКРАТНОМ ДИСТИЛЛЯЦИОННОМ ИЛИ КРИСТАЛЛИЗАЦИОННОМ РАФИНИРОВАНИИ ПРИ ЗАДАННОМ ВЫХОДЕ}

\section{А.И. Кравченко, О.А. Даценко}

Проведено сравнение концентрации $C_{\mathrm{n}}$ примеси с коэффициентом разделения $\beta<1$ в продукте $n$-кратного рафинирования простой дистилляцией или нормальной направленной кристаллизацией с концентрацией $C_{1}$ примеси в продукте однократного рафинирования с той же начальной концентрацией и тем же конечным выходом $G$. Показана зависимость $C_{\mathrm{n}} / C_{1}$ от параметров процесса $(n, G$ и $\beta)$, которая позволяет оценивать целесообразность применения $n$-кратного рафинирования взамен однократного. Превышение $C_{\mathrm{n}}$ над минимально достижимым уровнем растет с уменьшением $\beta<1$ и с увеличением $n$ и $G$.

\section{ПРО БАГАТОРАЗОВЕ ДИСТИЛЯЦИЙНЕ АБО КРИСТАЛІЗАЦІЙНЕ РАФІНУВАННЯ ПРИ ЗАДАНОМУ ВИХОДІ}

\section{О.І. Кравченко, О.А. Даценко}

Проведено порівняння концентрації $C_{\mathrm{n}}$ домішки 3 коефіцієнтом поділу $\beta<1$ у продукті $n$-кратного рафінування простою дистиляцією або нормальною спрямованою кристалізацією 3 концентрацією $C_{1}$ домішки в продукті однократного рафінування 3 тією ж початковою концентрацією і тим же кінцевим виходом $G$. Показана залежність $C_{\mathrm{n}} / C_{1}$ від параметрів процесу $(n, G$ і $\beta)$, яка дозволяє оцінювати доцільність застосування $n$-кратного рафінування замість однократного. Перевищення $C_{\mathrm{n}}$ над мінімально можливим рівнем зростає зі зменшенням $\beta<1$ і зі збільшенням $n$ і $G$. 